\title{
Celebrações e Linguagem na Imagem do Asilo de Infância Desvalida da Horta, Portugal, 1858-1910
}

\author{
Celebrations and Language on the Image of Asilo de Infância Desvali- \\ da da Horta, Portugal, 1858-1910
}

http://dx.doi.org/10.5007/2178-4582.2013v47n2p331

Sandro Serpa

Universidade dos Açores, Região Autónoma dos Açores, Portugal

\begin{abstract}
Neste trabalho discute-se o papel das celebrações e da linguagem mobilizada para o exterior, em contexto educativo, do Asilo de Infância Desvalida da Horta, Ilha do Faial, Açores, Portugal, numa análise diacrónica interpretativa, que abrange o período de 1858 a 1910 . O estudo foi concretizado através da consulta dos arquivos desta organização e de periódicos locais. Da análise da documentação consultada conclui-se que as celebrações e a linguagem utilizada na organização podem desempenhar um papel muito relevante no fomento da sua imagem positiva externa, o que pode revelar-se fundamental para a sua sobrevivência e continuidade.
\end{abstract}

Palavras-chave: celebrações e autodesignação organizacional; imagem organizacional; influência do exterior; organização educativa.
This paper discusses the role of celebrations and language mobilized to the exterior in the educational context of Asilo de Infância Desvalida da Horta, Faial Island, Azores, Portugal, in an interpretative diachronic analysis, from 1858 to 1910. The study was accomplished by consulting the archives of this organization and local newspapers. From the analysis of documentation consulted it follows that the celebrations and the language used in the organization can play an important role in nurturing its positive external image, which may prove crucial to its survival and continuity.

Keywords: celebrations and organizational self-designation; organizational image; outside influence; educational organization.

\section{Introdução}

Na cultura organizacional de uma instituição - entendida enquanto $\square \square]$ formas de sentir, de pensar e de fazer, partilhadas por um conjunto de pessoas, que são apreendidas, interpretadas, reproduzidas e produzidas ao longo do tempo pelos membros de um coletivo e conferem certos padrões de regularidade e de previsibilidade $\square$ (SERPA, 2013, p. 14)-, existem elementos simbólicos que a enformam $\square \square]$ uma estrutura composta por diferentes camadas de elementos (valores, normas, pressupostos fundamentais, padrões de comportamento, artefactos, etc.), unidos por um núcleo comum que é o significado" (NEVES, 2004, p. 446), abrangendo dimensões comportamentais, cognitivas, simbólicas e emocionais.

Estamos a referir-nos, por exemplo, a celebrações, linguagem, ou outros de maior ou menor visibilidade, tais como artefactos, padrões de comportamento, valores, crenças fundamentais, elementos estes que resultam de ações internas à organização, mas também de influências externas (COSTA, 2003; NÓVOA, 1995; OTT, 1989; SCHEIN, 2004; TORRES, 2011). De entre es- 
ses elementos, as cerimónias e a linguagem revelam-se de particular interesse considerando, por um lado, que, internamente, colaboram para um reforço da ordem organizacional cultural interna, e, externamente, para passar uma imagem positiva (reputação) da organização para o exterior, que promova o reconhecimento da sua ação e o envolvimento do exterior (DEAL; PETERSON, 2009; FREITAS, 2007; OTT, 1989), contribuindo, em maior ou em menor grau, conforme a organização e a situação em causa, para resolver, quer os processos de integração interna, quer a adaptação externa por parte da organização (SCHEIN, 2004).

Assim, esses elementos simbólicos são o reflexo das relações que a própria instituição estabelece ou pretende estabelecer com o exterior. Nestas relações com o exterior, que se desenvolvem, inevitavelmente, mesmo nas conjunturas de maior fechamento da organização (SERPA, 2013), elementos tais como as cerimónias e a linguagem (na sua forma e autodesignação utilizada em ocasiões especiais de contacto com o exterior), podem ser mobilizados, principalmente pelos dirigentes da organização, atendendo ao seu maior poder formal e real, enquanto maior capacidade de influenciar o outro, no sentido de conseguir uma imagem positiva da organização. Um exemplo da convocação desses elementos acontece quando se verifica a necessidade de, externamente, responder à obtenção de recursos materiais e humanos, na procura de legitimidade da ação que se desenrola na organização através do seu reconhecimento social. Esta mobilização revela ser, também, um fator importante a nível interno, na aprendizagem organizacional por parte dos seus membros, e no seu sentimento de pertença, aumentando o seu vínculo com a organização (FREITAS, 2007).

Ainda sobre as relações da organização com o exterior, estas ocorrem a dois níveis: (1) ao nível dos dirigentes e membros da organização de fora para dentro, quer naquilo que trazem de fora, a montante da sua entrada na organização, nomeadamente elementos da cultura de classe e/ou das culturas profissionais, quer nos contactos estabelecidos durante a sua pertença à organização; e (2) ao nível da organização para o exterior ao longo do tempo, através dos contactos institucionais ou sociais estabelecidos (SERPA, 2013).

Por outro lado, e reportando-nos a instituições de caráter assistencial infanto-juvenil - que nos interessam particularmente por constituírem o nosso objeto de estudo - as alterações que, com o tempo, existiram das representações sociais da infância e juventude desvalida, assim como o tempo socialmente vivido pelos indivíduos, coletivos e comunidade, constituem fatores que também podem influir nas próprias relações organização-exterior (GUEDES, 2006; LOPES, 2002; MOREDA, 1996; VILARINHO, 2000).

Concretamente, a assistência infanto-juvenil passou, ao longo dos tempos, por várias fases, mas desde meados do século XIX, o período que nos interessa aqui focar, é caracterizada por uma crescente presença do Estado (VILARINHO, 2000). Para além da importância da coletividade social, o Estado passa a atribuir a si próprio um papel central na assistência infanto-juvenil, oficiali- 
zando estes processos por meio de procedimentos formais e/ou jurídicos que assumiram várias formas de concretização.

Reportando-nos, especificamente, à instituição alvo do nosso estudo - o Asilo de Infância Desvalida da Horta -, neste contexto de análise e de tentativa de compreensão dos elementos simbólicos possivelmente subjacentes à imagem exterior construída durante os seus primeiros 52 anos de funcionamento, é nosso objetivo compreender qual a importância destes elementos, e qual a sua relação com o desenvolvimento de uma imagem positiva desta organização.

O Asilo de Infância Desvalida da Horta, atualmente designado como Casa de Infância de Santo António, foi fundado, na cidade da Horta, Ilha do Faial, Açores, Portugal, em 1858, com o objetivo de socorrer a probreza desamparada dos "expostos" do sexo feminino, tendo visto oficializada uma valência escolar, no ano de 1904, conhecida como Escola de Santo António, que era frequentada pelas asiladas (SERPA, 2013). Esta instituição, que se encontra em funcionamento atualmente, conta, neste momento, com várias valências - internato de crianças e jovens de ambos os sexos (desde 2008 pode acolher rapazes), creche, jardim-de-infância e escola do $1^{\circ}$ Ciclo do ensino básico.

A nível organizacional, desde a sua fundação, o Asilo foi gerido por uma Mesa Administrativa formada por cinco elementos, sendo que o seu Mordomo -Presidente era designado diretamente pelo Governador Civil do Distrito da Horta, e os restantes quatro elementos eram eleitos pelos Irmãos da Confraria de Santo António de Pádua e Asilo da Infância Desvalida da cidade da Horta, com nomeação do mesmo Governador Civil. Em alguns momentos de maior dificuldade na formação da Mesa Administrativa, o Governador Civil do Distrito da Horta escolhia diretamente uma Comissão Administrativa para gerir os destinos do Asilo. Ainda no que diz respeito ao organograma oficial, os Estatutos de 1860 e o Regulamento de 1876 estabeleciam a existência de uma Diretora do Asilo que superintendia diretamente o seu funcionamento, tinha autoridade sobre os outros empregados e era, simultaneamente, Professora das asiladas; e, ainda, um capelão inerente à Confraria, de nomeação e destituição direta pelo Governador Civil do Distrito da Horta, sob aprovação do Prelado Diocesano (ASILO DE INFÂNCIA, 1876), fator que reforça, confirmando, a presença da Igreja Católica nesta organização e a importância e autonomia do Capelão, quer perante a Mesa Administrativa, quer perante o MordomoPresidente.

Em organizações com características similares às do Asilo em análise, as influências do meio, quer de modo mais direto da comunidade - por exemplo, ao nível de apoios concedidos -, quer de uma forma mais indireta, naquilo que os atores trazem do exterior, não podem fazer esquecer que o Asilo assume, concomitantemente, um papel ativo na forma como a comunidade o perspetiva, sendo que, atualmente, e de uma forma geral, poderá não existir uma rutura tão acentuada com o exterior (DIOGO, 2008; MARTÍNEZ et al. , 2005).

Nesta ordem de ideias, procurar-se-á, neste trabalho, focar o papel de algumas das manifestações culturais, num contexto educativo específico - o Asi- 
lo de Infância Desvalida da Horta -, no período compreendido entre os anos de 1858, ano da sua fundação e consolidação, e 1910, ano da implantação da República em Portugal: as celebrações enquanto momentos de comemoração da organização e de abertura desta ao exterior; e a linguagem, quer na autodesignação, quer no tipo de linguagem mobilizada pelos membros da sua administração em contactos mais relevantes com o exterior. Com esta análise, pretende-se, em síntese, aprofundar o estudo destes elementos da cultura organizacional desta instituição e a forma como eles se relacionam com a imagem que essa mesma organização reflete no contexto onde se insere.

\section{A mobilização de celebrações e da linguagem nos primeiros 50 anos do Asilo de Infância Desvalida da Horta}

A presente pesquisa, que abarca um período temporal de 1858 a 1910, foi sustentada por um estudo documental, essencialmente por meio da consulta do arquivo da Casa de Infância de Santo António (atual designação do Asilo de Infância Desvalida da Horta) e de periódicos locais da época. Durante este período (1858-1910) o contexto interno é precário, inicialmente muito dependente de financiamento privado, fator que motiva, também, a necessidade de manutenção de boas relações com o exterior no fomento de uma imagem positiva do Asilo através das celebrações e da linguagem utilizada, como veremos adiante.

\section{Celebrações}

No que diz respeito às celebrações de caráter organizacional, o Asilo, ao longo dos seus anos de existência, revelou uma dedicação particular a festas e celebrações, de índole religiosa a maior parte delas, algumas das quais de maneira mais acentuada e sistemática do que outras, na procura de promover momentos, simultaneamente, de celebração do Asilo e de abertura (controlada) deste ao exterior. Logo aquando da fundação do Asilo de Infância Desvalida da Horta, em 28 de dezembro de 1858, regista-se: $[\square$ ] celebrando-se a instalação com uma solemne festa a que assistiram o conselheiro governador civil e os principaes da ilha que offereceram ás azyladas um lauto jantar [almoço] $\square$ (MACEDO, 1981, p. 256).

A relevância das celebrações nesta organização também se torna visível a nível normativo desde muito cedo. Como fica registado no Regulamento de 1876, o Natal, a Páscoa, o dia de Santo António e o aniversário da fundação do

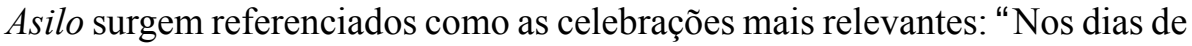
natal, de paschoa, e nos da festividade de Santo António, padroeiro do azylo, e anniversario da inauguração do mesmo, terão as azyladas mais um prato de comida $\square\left(\right.$ Artigo $108^{\circ}$ ).

Contudo, ao longo dos tempos é possível identificar, na documentação consultada, que são duas as festividades que virão a constituir-se como as 
principais comemorações do Asilo enquanto organização: a festa de Santo António e a festividade dos Santos Inocentes, no dia 28 de dezembro, data que celebra a inauguração da instituição. Pela relevância e notoriedade que adquirem na história desta organização, centrar-nos-emos mais detidamente nelas.

A centralidade e importância destas festas verificam-se pela grande mobilização do Mordomo-Presidente e da Mesa Administrativa (ou Presidente e respetiva Comissão Administrativa) em prol da sua concretização; pela importância e dimensão participativa visíveis nos convites, agradecimentos e publicitações, cuja componente religiosa é muito forte e manifesta; e pelas celebrações que foram acontecendo sempre na Igreja anexa ao Asilo (SERPA, 2013).

No que se refere à celebração de Santo António, esta já acontecia ainda antes da inauguração do Asilo, como fica registado, a 24 de junho de 1858, na Resposta do Comandante da Subdivisão militar da Horta ao convite para a festa de Santo António e à solicitação de acompanhamento militar (ASILO DE INFÂNCIA, 1862), verificando-se a sua continuidade até aos dias de hoje. A título de exemplo, durante o período da gestão da Mesa Administrativa do primeiro Mordomo-Presidente da instituição, esta festa de Santo António decorria com trezenas (orações que se fazem em louvor a Santo António nos treze dias antecedentes à sua festa), e, no dia da festividade, com missa cantada, com sermão de manhã e o complemento das trezenas de tarde, também com sermão (SERPA, 2013). Segundo o Relatório do Governador Civil Santa Rita para o Bispo, datado de 21 de dezembro de 1872: Thavendo Sacramento exposto, e no dia da festividade dois sermões, um de manhã, e outro de tarde (MEMORIA [...], 1884, p. 65).

Nesta festa de Santo António era tradição que o jantar $\square$ (designação, na época, para almoço) das asiladas, no dia da comemoração, fosse oferecido por beneméritos e servido e assistido por pessoas que podiam ser externas ao Asilo, como se pode verificar no exemplo que se segue:

\footnotetext{
No domingo ultimo celebrou-se na egreja de Santo António a festa, que se dedica a este santo e que não ponde realisar-se no dia proprio. Houve bastante concorrencia.Ao jantar das asyladas assistiram alguns cavalheiros e muitas pessoas do povo. Antes do jantar cantaram as creanças um hymno em louver a Deus por as ter salvado da miseria e da fome. É um acto edificante e que internece (O FAYALENSE, Noticias Locaes, 1862, p.4).
}

Constituía costume, igualmente, o Asilo estar aberto nesse dia a quem o quisesse visitar, com a possibilidade de examinar os livros de contas (SERPA, 2013), numa lógica de a organização se revelar merecedora de confiança de quem a possa querer apoiar, como se lê no seguinte excerto: 
examinados, não so pela irmandade, mas tambem por todas as pessoas que n'isso tenham algum interesse (O FAYALENSE, Annuncios, 1872. p.4).

A festividade de Santo António aconteceu, durante todo o período em estudo, com uma organização e características similares, mesmo tendo sido organizada por diferentes Mesas ou Comissões Administrativas. A festividade de Santo António acontecia, em regra, com a abertura da festa ao público em geral; a preparação religiosa na Igreja de Santo António, anexa ao Asilo; com convites a várias personalidades que assistiam à missa; com uma missa da festa; com a distribuição de prémios às asiladas; com almoço aos convidados; com o almoço das asiladas, servido por personalidades e assistido pelo público em geral; e com o Asilo franco ao público (SERPA, 2013).

Por seu turno, no que se refere à celebração do aniversário da inauguração do Asilo, no dia 28 de dezembro, esta era, em todas as presidências deste período, associada à festividade dos Santos Inocentes, naquilo que constitui mais uma imbricação da dimensão religiosa na cultura da organização. Para esta festa, à semelhança daquilo que acontecia na de Santo António, o Governador Civil era comummente convidado, bem como outras autoridades e benfeitores específicos. Verificam-se, igualmente, solicitações a Filarmónicas e outros músicos para atuarem nesta festividade da comemoração do aniversário da inauguração do Asilo (SERPA, 2013). A festividade dos Santos Inocentes decorria com missa cantada e sermão, também com o jantar público das asiladas e com o Asilo aberto à comunidade (O FAYALENSE, Annuncios, 1864, p.4).

Quer as festas de Santo António, quer as dos Santos Inocentes eram abertas ao público, com uma forte componente religiosa, e aconteciam, quase sempre, na Igreja de Santo António. A presença de público, particularmente na festa de Santo António, devia ser, em certos anos, elevada, e, por vezes, geradora de desordens, atendendo à constância de o Mordomo-Presidente requerer vigilância de elementos de forças de segurança para a manutenção da ordem na Igreja e no Asilo durante os dias santificados de trezenas e no dia da própria festa (SERPA, 2013).

Nessas cerimónias, a participação das asiladas, de uma forma controlada, era desejável, como forma de mostrar à comunidade o zelo e os cuidados que lhes eram prestados. Esta situação é notória, por exemplo, até nos próprios normativos da organização, que definem a forma como as asiladas devem estar vestidas e como se devem comportar em situações de contacto com o exterior. Como se lê no Regulamento de 1876, existe um $[\square$ ] facto especial que as azyladas terão para assistirem ás festividades que se celebrarem na egreja d'este azylo" (Artigo 63) e no Artigo $147^{\circ}$. 
das as festividades que se celebrarem na egreja do azylo, ou a quaesquer actos publicos a que as mesmas tenham de assistir, tendo sempre o cuidado que ellas estejam em bôa ordem, com attenção e respeito (ASILO DE INFÂNCIA...1876)

Tais celebrações eram, sem dúvida, formas de a organização se relacionar controladamente com uma comunidade da qual dependia, em grande medida, também a nível financeiro, por meio da promoção de uma imagem pública positiva, o que parece ser conseguido, como se evidencia na opinião publicada em algumas edições do jornal $O$ Fayalense, respeitantes a diversos anos: $\square \square$ ] o asylo esteve durante o dia franco às pessoas que o queriam visitar, estando tudo com muito acceio e ordem" (O FAYALENSE, Festas Religiosas, 1876, p.4), repetindo-se esta situação em anos seguintes (Id., Santo António, 1877, p.4); "[...] o edificio esteve durante o dia aberto a quem o quis visitar, notando se em tudo muita ordem e aceio $\square$ (Id. Outra, 1882, p.4).

Correu tudo admiravelmente, cantando as educandas a missa por forma bastante apreciavel. Todo o edificio do asylo achavase em excellente ordem apresentando as educandas um magnifico aspecto, o que muito honra a direcção d'aquelle pio estabelecimento (O TELEGRAPHO, 1905, p.1).

\section{Linguagem}

A linguagem diz respeito às formas que a designação ou o nome do Asilo foi adquirindo ao longo da sua existência e que evidencia, no período em causa, uma clara tentativa de vincular o exterior à instituição. Numa altura em que Portugal vivia num período monárquico, as pequenas nuances que o nome foi revelando procuram, em qualquer caso, garantir o apoio externo que permita a manutenção da instituição.

Essa necessidade de vinculação é visível logo a 8 de maio de 1859 , quando é solicitada autorização para a utilização da designação de $\square$ Dom Luiz I $\square$ no seu nome, por força da visita deste monarca, ainda Infante, à ilha do Faial, lendo-se num registo da época:

[...] deve ficar registado em nossos corações por um documto. que passe atravez dos seculos. A Com ${ }^{\mathrm{am}}$. Admenistrativa do Azylo d'Infancia Desvalida estabelecido no edificio do extincto Convento de $\mathrm{S}^{\text {to }}$. António d'esta Cidade, pelo actual $\mathrm{G}^{\text {or }}$. Civil o Conselheiro António Joze Vieira $\mathrm{S}^{\text {ta }}$. Rita, $\mathrm{p}^{\mathrm{a}}$. cuja instituição Vossa Alteza concorrêo com uma esmola, tem pois a distincta honra de rogar a Vossa Alteza Real se Digne permittir, que o novo Azylo tome o nome de Vossa Alteza Real [...] (ASILO DE INFÂNCIA, 1862). 
Mesmo considerando-o como "Protector" do Asilo da Infância Desvalida da Horta no Pedido da designação Dom Luiz para o Asilo, a 8 de maio de 1859 (Ibid.), não foram encontrados registos de qualquer resposta que torne essa vinculação efetiva (LEMOS, 1958; SERPA, 2013). Ainda, nos Estatutos de 1860, Capítulo $9^{\circ}$, Artigo 57, é referido que O Azylo de Infancia desvalida, existente no edificio do extinto Convento de $\mathrm{St}^{\circ}$ António tomará o nome Azylo do Infante, o Senhor Dom Luiz $\square$ como memoria da visita que Sua Altesa Real se Dignou Fazer a esta ilha no mes de Novembro de 1858 (ASILO DE INFÂNCIA, 1860).

A utilização da designação Dom Luiz, não sendo generalizada, acontece em variadas situações de correspondência, nas quais surge com particular interesse este realce, tais como:

- em convites, associando-se Dom Luiz a "Protector" do Asilo - "a cargo do Asylo da Infancia Desvalida desta Cidade, de quem é Protector Sua Altesa Real, o Sr. Infante D. Luiz Duque do Porto", por exemplo, ao convite ao Governador Civil para assistir às festividades de Santo António, a 14 de junho de 1861 (Id.,1862); Convite ao Governador Civil para assistir às festividades dos Santos Inocentes, de 26 de dezembro de 1863; Convite ao Governador Civil para assistir às festividades de Santo António, de 14 de junho de 1878 (ASILO DE INFÂNCIA, 1870; 1878);

- em solicitações ao Rei D. Pedro V, onde este capital simbólico é mobilizado - "o referido Asylo da Infancia Desvalida ennobrecido com a destincta honra de ter $p^{r}$. Padroeiro e Protector a Sua Alteza Real, o Serenissimo Senhor Infante D. Luiz Duque do Porto, Augusto Irmão de Vossa Magestade" numa solicitação ao Rei D. Pedro V de imagens e ornamentos que se encontram no Convento da Glória para a Igreja de Santo António, a 4 de março de 1861 (Id., 1862);

- em documentação de contabilidade - por exemplo, no Mapa dos rendimentos e despesas do Asilo exigido pelo Governador, onde se verifica a denominação: $\square$ Asylo do Infante o $\mathrm{S}^{\mathrm{r}}$. D. Luiz" no envio ao Governador do mapa dos rendimentos e despesas do Asilo exigido pelo Governador a 19 de dezembro de 1861, com data de 7 de janeiro de 1862 (Id. Ibid.); ou num documento sobre a venda da cerca do Asilo, onde é referido que o Rei aceitou ser seu Protetor para travar a venda da cerca, de 2 de maio de 1877 (Id., 1878);

- em felicitações - como a de 24 de novembro de 1862, onde a Mesa Administrativa do Asilo deu, ao Rei D. Luiz $1^{\circ}$ pelo seu consórcio, a $\$ Sua Real Protecção $\square$ aquando da visita, acrescentando e do qual tambem é hoje Protectora A Nossa Augusta Soberana $\square$ na felicitação ao Rei D. Luiz $1^{\circ}$ pelo seu consórcio (Id., 1870).

Em mais uma ilustração do poder do simbolismo da designação $\square$. Luís $\square$ a morte de Dom Pedro V, seu irmão, motivou que fosse dado "um testemunho publico do doloroso sentimento [ $\square$ ] Irmão do Real Padroeiro, e Protector d este Pio Estabelecimento, El-Rei o $\mathrm{S}^{\mathrm{r}}$. D. Luiz; e bem assim de mostrar o reconhecimento dos beneficios recebidos neste humanitario estabelecimento" 
numa solicitação ao Governador para assistir à missa por D. Pedro V, datada de 19 de dezembro de 1861 (ASILO DE INFÂNCIA, 1862).

A necessidade de ligação a uma figura de relevo fica, igualmente, patente durante as presidências seguintes, verificando-se a continuação da mobilização da referência a Dom Luís nas relações estabelecidas com o exterior. Como exemplo, na sessão de 7 de fevereiro de 1884, refere-se a situação precária do Asilo de Infância Desvalida da Horta $\square$ D. Luiz $\square$ plasmada numa ata, que motivou diversas solicitações de apoio e que culminou com a resolução de uma solicitação de auxílio, quer ao Papa Leão XIII, chefe da egreja catholica romana $\square$, mobilizando o nome $\square$ asylo do infante D. Luiz $\square$ quer a El-Rei D. Luiz I, como irmão protector deste estabelecimento $\square$ (Id., 1897).

A referência à figura de Dom Luís também está claramente patente na relação com a comunidade. Um bom exemplo disso é a inauguração dos retratos de Suas Altezas, o Príncipe Real Dom Carlos e a Augusta Princesa Sua Esposa Dona Maria Amélia, ao lado dos retratos já expostos do Rei e da Rainha, por comemoração do seu casamento (Sessão de 16 de junho de 1886). Nesta inauguração, que aconteceu com sessão solene a 25 de junho de 1886, estiveram presentes numerosas autoridades, tendo sido oferecido um jantar $\square$ (almoço) às asiladas pelo Governador Civil do Distrito da Horta, o que conferiu grande visibilidade ao Asilo (Ibid.).

A partir da descrição detalhada desta inauguração, registada nesta ata de 25 de junho de 1886, podem retirar-se algumas ilações sobre a imagem que o Asilo projetava, à data, para o exterior. Assim, destacamos:

- a mobilização da autodesignação $\llbracket$ Asylo do Infante Dom Luiz $\square$, como tendo um grande valor simbólico positivo no meio social, a julgar pelas palavras do Mordomo-Presidente - "esta instituição, que se orgulha com o nome de Asylo do Infante Dom Luiz ;

- o facto de se tratar de um momento de grande festividade, ao qual não se podia faltar, com a atribuição de uma grande importância às personalidades exteriores ( $\square$ achando-se presentes grande numero de senhoras e cavalheiros $\square$ );

- a manifestação de respeito e de aceitação da ordem social vigente, na pessoa das autoridades locais, como é relatado nesta ação do Mordomo-Presidente e restante Mesa Administrativa - "tendo conhecimento de que se approximava d'este edificio o mesmo excelentissimo Governador civil, o presidente da câmara municipal e auctoridades, convidados para solennizar este acto, se dirigiu, com os vogaes da mesa a esperar fóra das portas a suas excelencias e conduzil-os a esta sala"; perante esta situação, o Mordomo-Presidente convidou o Governador Civil a assumir a presidência da sessão, que recusou, tendo, de seguida, convidado o Presidente da Câmara, que também recusou, convidando, ainda, estas duas individualidades para destapar dois retratos;

- a mobilização das asiladas neste evento, num jantar $\square$ (almoço) que teve lugar após a inauguração dos retratos, oferecido pelo Governador Civil, durante o qual os convidados tiveram a portunidade de as ouvir, cantando as asyladas os hymnos de Suas Magestades, e um hymno dedicado a Suas Alte- 
zas $\square$ e que concluiu com a leitura que uma asilada fez de uma mensagem de Felicitações a Sua Majestade escrita por outra asilada.

Posteriormente, e sob a alçada de um outro Mordomo-Presidente, verifica-se a mobilização da designação Infante Dom Luiz em questões formais de maior visibilidade, tais como em situações de solicitação ao exterior, mormente a entidades oficiais. Esta situação é evidente, por exemplo, no certificado de conduta passado pela Mesa Administrativas à Diretora do Asilo, no qual se lê accordam os da meza administrativa do asylo de Infancia Desvalida do Infante O Senhor Dom Luiz na cidade da Horta" (Sessão extraordinária de 28 de março de 1904), ou, conforme é referido na sessão extraordinária de 14 de abril de 1904, na petição dirigida ao Rei para nomeação da Diretora do Asilo como professora da escola oficial, fazendo-se referência, por duas vezes, ao Infante D. Luiz na autodesignação - $\square$ Asylo de Infancia Desvalida, Infante D. Luiz, da cidade da Horta" e "asylo de Infancia Desvalida, Infante D. Luiz" (ASILO DE INFÂNCIA, 1912).

Surge, de igual modo, a mobilização da designação $\square$ Asylo d Infancia Desvalida do Infante Dom Luiz", na cidade da Horta, ou, mais pormenorizadamente, "meza administrativa da Confraria de Santo António de Padua e Asylo d Infancia Desvalida do Infante Dom Luiz $\square$, com variações, na solicitação de retratos a beneméritos (abril de 1906), no agradecimento de donativos (28 de fevereiro de 1907 e 12 de junho de 1907), e, em correspondência oficial, com o Governador Civil (12 de março de 1907) ou com outras entidades (Informação sobre o Asilo, 9 de setembro de 1908) (Id., 1913).

\section{Conclusão}

Da análise da documentação efetuada destaca-se, em primeiro lugar, e sobre as relações com o exterior, uma manifesta necessidade de a instituição manter uma proximidade com o Estado, quer pelas necessidades financeiras existentes, quer, também, pela necessidade de apoio político, uma vez que era o Governador Civil quem decidia sobre a manutenção ou não do Mordomo -Presidente e da Mesa Administrativa em funções. Ao longo deste período, são evidentes as dificuldades económicas sentidas e, para as colmatar, as Mesas Administrativas socorreram-se, inicialmente, de financiamento privado, tendo, progressivamente, passado a contar com algumas receitas próprias e com alguns apoios estatais, que geram essa relação de dependência e a necessidade evidente e premente de aproximação com elas.

Em segundo lugar, e numa síntese que se pretende elucidativa de alguns elementos simbólicos da cultura organizacional desta instituição, nomeadamente das celebrações, e da linguagem, os resultados do estudo permitem concluir que, de 1858 a 1910, se verificou uma tentativa de clara aproximação ao exterior.

Quanto às cerimónias, é de realçar a de Santo António e a dos Santos Inocentes, coincidente com a data de aniversário da fundação do Asilo. No que 
se refere à linguagem, a autodesignação utilizada inclui, sistematicamente, a referência a Dom Luís $\square$, sendo um exemplo frequentemente encontrado o de Asilo de Infância Desvalida da Horta do Infante Dom Luís e Confraria de Santo António de Pádua (com variações).

Muitas das comemorações são utilizadas, também, para dar maior visibilidade ao trabalho que é desenvolvido na organização, concorrendo para influenciar, no sentido de melhorar, a sua imagem externa. A dependência de apoios privados é muito central nas relações de caráter institucional que o Asilo estabelece com o exterior, quer na solicitação de coadjuvação, quer nos agradecimentos de donativos, quer, ainda, no fomento da relação com benfeitores (SERPA, 2013).

A forma como os Mordomos-Presidentes, Presidentes, as respetivas Mesas Administrativas e as Comissões Administrativas perspectivam a sua relação com o exterior encontra-se diretamente relacionada com as condições de imagem social que a instituição sente necessidade de difundir para o exterior. O papel desempenhado por particulares e pelo Estado (em termos de suporte financeiro, mas, também, jurídico) é manifestamente central na relevância atribuída às celebrações e à autodesignação na relação Asilo-exterior e, mesmo, no seu interior.

Em síntese, a manutenção do Asilo de Infância Desvalida da Horta, nos seus primeiros 52 anos de vida, com um claro mandato de assistência e acolhimento de meninas desfavorecidas, envolveu a mobilização de celebrações e de linguagem, principalmente por parte das suas diversas gerências, atendendo à sua capacidade formal e real de representar o Asilo. Tanto as celebrações como a linguagem foram sofrendo algumas variações conforme o contexto externo e interno da organização se alterava, muito por força da ótica dos seus dirigentes, procurando integrar o meio interno e adaptá-lo ao meio externo (SCHEIN, 2004) e articulando o controlo interno com uma imagem positiva externa, atendendo, também, à sua necessidade de sobrevivência.

\section{Referências}

ASILO DE INFÂNCIA DESVALIDA DA HORTA. Registo de Officios recebidos no Asylo de Infância Desvalida. Desde 1858 a 1862 . Horta: 1862.

. Correspondência expedida do Asylo de Infância Desvalida. Desde 26-5-1862 a 30-71870. Horta: 1870 .

Estatutos da Confraria de $S^{\text {to }}$. António e Azylo de Infância Desvalida. 10 de Janeiro de $\overline{1876}$ (contém: Estatutos da Confraria de $\mathrm{S}^{\text {to }}$. António e Azylo de Infancia Desvalida da cidade da Horta, de 1860, e o Regulamento interno do Azylo da infancia desvalida, annexo á irmandade de Santo António de Padua, erecta no extincto convento do mesmo Santo, na cidade da Horta, da ilha do Fayal, de 1876). [Por nós designados Estatutos de 1860 e Regulamento de 1876, respetivamente]. Horta: 1876.

Cópia de Ofícios da Confraria de Santo António e Asylo de Infância Desvalida. Desde $\overline{\text { Abril de }} 1872$ a 14/6/1878. Horta: 1878. 
SERPA, Sandro. Celebrações e Linguagem na Imagem do Asilo de Infância Desvalida da Horta, Portugal... ta: 1897.

. Actas do Asylo de Infância Desvalida da Horta. Desde 1-10-1883 a 7-4-1897. Hor-

Actas da Confraria de Santo António de Pádua e Asylo do Infante Dom Luis. Desde 1-7-1903 a 4-9-1912. Horta: 1912.

Correspondência expedida da Confraria de S. António de Pádua e Asylo de Infância Desvalida. Desde 2-1-1905 a 31/12/1913. Horta: 1913.

COSTA, Jorge Adelino. Imagens organizacionais da escola. Porto: ASA, 2003.

DEAL, Terrence ; PETERSON, Kent. Shaping school culture: pitfalls, paradoxes, and promises. San Francisco: Jossey-Bass, 2009.

DIOGO, Ana Matias. Dinâmicas e práticas institucionais. Organização interna e educação. In: ROCHA, G. P. N. (Coord.); MEDEIROS, O. H. R.; DIOGO, F.; DIOGO M. Socializações alternativas. Crianças e jovens em instituições nos Açores. Ponta Delgada: Centro de Estudos Sociais da Universidade dos Açores, 2008. p.169-202.

FREITAS, Maria Ester. Cultura organizacional: evolução e crítica. São Paulo: Thomson Learning, 2007.

GUEDES, Ana Isabel Marques. Os Colégios dos meninos órfãos (Sécs. XVII-XIX). Évora, Porto e Braga. Lisboa: Imprensa de Ciências Sociais, Instituto de Ciências Sociais da Universidade de Lisboa, 2006.

LEMOS, Raimundo Rodrigues Garcia. de. Asilo de Infância Desvalida da Horta. 1858-1958. Horta: 1958.

LOPES, Maria Antónia. Crianças e jovens em risco nos séculos XVIII e XIX. O caso português no contexto europeu. Revista de História da Sociedade e da Cultura, Coimbra, v. 2, n.2, p.155$184,2002$.

MACEDO, António Lourenço da Silveira. História das quatro ilhas que formam o Distrito da Horta. (Vol. II). Angra do Heró́smo: Direcção Regional dos Assuntos Culturais da Secretaria Regional da Educação e Cultura da Região Autónoma dos Açores, 1981.

MARTÍNEZ, Ricardo. et al. (Coord). Estruturas de acolhimento de crianças e jovens em Lares. Contributo para o estudo de modelos e modos de resposta. In: CONSELHO TÉCNICO-CIENTÍFICO DA CASA PIA DE LISBOA. Casa Pia de Lisboa $\square$ Um projecto de esperança. As estratégias de acolhimento das crianças em risco. Cascais: Principia, Publicações Universitárias e Científicas, 2005. p.395-522.

MEMORIA histórica sobre o azylo d'infancia desvalida da cidade da Horta. Horta: Typographia de V. A. L. Silveira. 1884.

MOREDA, Vicente Pérez. (Coord.). Expostos e ilegítimos na realidade ibérica - do século XVI ao presente. Porto: Edições Afrontamento, 1996.

NEVES, José. Clima e cultura organizacional. In: FERREIRA, J. M. C.; NEVES, J.; CAETANO, A. (Coords.) Manual de psicossociologia das organizações. Lisboa: Editora McGraw-Hill de Portugal, 2004. p.431-468. 
NÓVOA, António. Para uma análise das instituições escolares. In NÓVOA, A. (Org.) As Organizações Escolares em Análise. Lisboa: Publicações Dom Quixote e Instituto de Inovação Educacional, 1995, p.13-43.

O FAYALENSE. Noticias Locaes. Horta, 29 de jun. 1862. p.4. . Annuncios. Horta, 25 dez. 1864. p.4. . Annuncios, Horta, 9 jun. 1872. p.4. . Festas Religiosas. Horta, 25 jun. 1876. p.4. . Santo António. , Horta, 24 de jun. 1877. p.4. Outra. Horta, 18 de jun. 1882. p.4

O TELEGRAPHO. Santo António. Horta, 26 de jun. 1905. p.1.

OTT, J. Steven. The organizational culture perspective. Chicago: The Dorsey Press, 1989.

SCHEIN, Edgar H. Organizational culture and leadership. San Francisco: Jossey-Bass, 2004.

SERPA, Sandro. Dinâmicas nas (re) configurações da cultura organizacional. A Casa de Infância de Santo António (1858-2008). 2013. 474 f. Tese (Doutorado em Educação, na especialidade de Sociologia da Educação) - Universidade dos Açores. Angra do Heroísmo.

TORRES, Leonor Lima. Cultura organizacional em contexto escolar. In LIMA, L. C.; SILVA, E. A.; TORRES, L. L.; SÁ, V.; ESTEVÃO, C. V. Perspectivas de análise organizacional das escolas. Vila Nova de Gaia: Fundação Manuel Leão, 2010, p.109-152.

VILARINHO, Maria Emília. Somos gente! As crianças entre a família, o estado e a sociedade. Fórum Sociológico, Lisboa, n. 3/4 (II ${ }^{\mathrm{a}}$ série), p.95-112, 2000.

Submissão em: 24/10/2013

Revisão em: 19/03/2014

Aceite em: 19/03/2014

Sandro Serpa é Professor Auxiliar do Departamento de Ciências da Educação e pesquisador do Centro de Estudos Sociais da Universidade dos Açores. É doutor em Educação, especialidade Sociologia da Educação. Endereço para correspondência: Departamento de Ciências da Educação, Universidade dos Açores. Campus de Ponta Delgada. Apartado 1422. PT 9501-801. Ponta Delgada, Açores. Portugal. E-mail: sandroserpa@uac.pt 